\title{
Innovative Control Technique for the Floor Heave in Goaf-Side Entry Retaining Based on Pressure Relief by Roof Cutting
}

\author{
Guangyuan Yu $\mathbb{D}^{1,2}$ Jiong Wang ${ }^{10},{ }^{1,2}$ Jinzhu Hu, ${ }^{1,2}$ Daoyong Zhu, ${ }^{1,2}$ Han Sun, ${ }^{1,2}$ \\ Xingen $\mathrm{Ma}^{1,3}$ Wei Ming, ${ }^{1,2}$ and Wenfei $\mathrm{Li}^{1,2}$ \\ ${ }^{1}$ State Key Laboratory of Geomechanics \& Deep Underground Engineering, China University of Mining \& Technology, \\ Beijing 100083, China \\ ${ }^{2}$ School of Mechanics and Civil Engineering, China University of Mining \& Technology, Beijing 100083, China \\ ${ }^{3}$ Huaneng Coal Technology Research Co., Ltd, Beijing 100070, China
}

Correspondence should be addressed to Jiong Wang; wangjiong0216@163.com

Received 8 July 2021; Accepted 9 August 2021; Published 19 August 2021

Academic Editor: Feng Xiong

Copyright ( 2021 Guangyuan Yu et al. This is an open access article distributed under the Creative Commons Attribution License, which permits unrestricted use, distribution, and reproduction in any medium, provided the original work is properly cited.

To solve the difficulty in controlling floor heave of a retained goaf-side roadway, a new control technique was investigated from the perspective of the pressure relief by roof cutting by combining mechanical analysis, numerical simulation, and engineering tests. The mechanical principle of controlling the floor heave based on pressure relief by roof cutting was attained by analyzing the movement of overlying strata and mechanical characteristics of key blocks before and after the roof cutting. A new technique for controlling the floor heave based on pressure relief by roof cutting was proposed. Research results have shown that after performing pressure relief by roof cutting, the caved gangues in the goaf can support the overlying strata and, thereby, change the movement law thereof and weaken the abutment pressure on the coal wall. Furthermore, the pressure exerted on the roadway floor by the coal wall is lowered to prevent plastic deformation of the floor, thus controlling floor heave in the roadway; a new integrated technique for controlling the floor heave based on pressure relief by roof cutting, flexible yielding, controlling with double-direction-control anchor bolts, and controlling with reinforcing anchor cables is developed, and the technological processes of support, cutting, and protection are summarised. The results of field testing showed that, after applying the new technique, the average floor heave amount of the roadway declines by $64 \%$ and the average speed of the floor heave up to $231 \mathrm{~m}$ behind the working face decreases by $61 \%$.

\section{Introduction}

Gob-side entry retention (GER), as an important technique in coal mining system without pillars [1-4], can improve the recovery rate of coal resources, reduce the rate of tunnelling of roadways, and avoid the waste of resources [5], owing to which it has been widely used in various coal mines in countries such as China, Germany, Poland, and the United Kingdom and has achieved remarkable economic and social benefits [6]. As a conventional material for roadway sidewall supporting, concrete blocks are characterised by large support resistance in the early stage, large rate of increase in resistance, favorable roof-cutting effect, and favorable sealing effect of the goaf. They are widely used in goaf-side entry retaining [7]. However, different degrees of floor heaves occur in nearly all retained goaf-side roadways including those by building concrete blocks alongside. With the increase in mining depths and roadway cross-section, the floor heave increases [8]. Especially for soft rock roadway, not only does it have a low strength but it also exhibits extremely strong rheology and undergoes large creep deformation, including that of severe extrusion [9]. As a result, the roadway floor cannot be reused as often. A small portion of roadway floors is hard to repair, or are beyond repair, thus causing the failure of gob-side entry retaining. This greatly affects the safe and efficient mining of the coal face [10].

The most commonly used techniques to control floor heave of roadways are reinforcement and pressure-relief 
methods. In terms of the former, the following studies have been conducted: Bai et al. [11] proposed to control floor heave by reinforcing the floor using hydraulic expansion bolts anchored through their length. He et al. [12] proposed a floor heave control technique focusing on controlling the roof, two sidewalls, and base angle. Liu et al. [13] came up with a comprehensive method, involving the use of a reverse-arch concrete floor, grouting in deep and shallow holes, and highly prestressed, combined cables, aiming to control floor heave of roadways in fractured soft rock mass found in deep mines. By analyzing the effects of multiple means of controlling floor heave in deep roadways, Xie and Chang [14] proposed the use of overexcavation and grouting-backfilling to control floor heave and deformation. As for pressure-relief methods, Gao et al. [15] controlled floor heave of roadways through blasting pressure relief in deep boreholes drilled from the floor. Sun [16] proposed to control floor heave of roadways by pressure relief via cutting grooves at base angles of roadways. Zhao et al. [17] studied floor heave in a mining roadway beneath a goaf-surrounded coal pillar and proposed the control of the floor heave in the roadway by pressure relief through drilling boreholes from the floor beside the coal pillar, while grouting reinforcement was used in the floor near the goaf. Based on theoretical analysis and numerical simulation, Gong et al. [18] derived a method to control floor heave of a roadway through pressure relief by drilling boreholes from the sidewalls of the roadway. Han et al. [19] proposed to control floor heave in mining roadways by excavating a pressure-relief groove on the floor. Wang et al. [20] used hydraulic fracturing to cut the roadway roof, thus reducing the floor heave. Although numerous studies have been undertaken on the techniques available to control floor heave in roadways, the proposals focus on two aspects: reinforcement and pressure relief. Despite certain inhibitory effects on the floor heave, the reinforcement methods fail to weaken the driving force of the floor heave. Although the pressure-relief methods allow floor strata to be located in a stress-reduction zone by loosening blasting, groove cutting, and borehole drilling, they are also likely to enlarge the plastic zone in surrounding rocks of roadways, which is unbeneficial to the maintenance of the roof and sidewalls [21]. Meanwhile, the hydraulic fracturing can make the rock strata to undergo shear or tensile failure along the primary fracture [22], but it also has drawbacks such as huge construction volumes, slow speed, and low efficiency [23]. In comparison, the bidirectional cumulative tensile blasting method, as a type of the cumulative blasting technique, is characterized by advantages including small construction volumes, favorable shaping effect, little damage to surrounding rocks, and use of a low specific charge [24]. Many researches indicate that roof cutting through bidirectional cumulative tensile blasting can optimize the stress state in the rock surrounding a roadway $[25,26]$, so it is expected to become a new technique for controlling floor heave in gobside entries.

On this basis, against the background of a conveyor gateway in the working face of a retained goaf-side roadway by building concrete blocks beside in Faer Coal Mine, the aim of this study were threefold: (1) the movement of overlying strata and mechanical characteristics of the floor of the retained goaf-side roadway before and after pressure relief by roof cutting were explored through theoretical analysis and numerical simulation. Furthermore, the mechanical principle of controlling floor heave by the virtue of pressure relief by roof cutting was obtained; (2) a new integrated technique for controlling floor heave combining pressure relief by roof cutting, flexible yielding, controlling with double-direction-control anchor bolts, and controlling with reinforcing anchor cables, based on pressure relief by roof cutting, was proposed; moreover, the technological processes of support, cutting, and protection were determined, and the field test was conducted; (3) the field monitoring revealed that the average floor heave amount of the retained goaf-side roadway with the new technique dropped by $64 \%$, and the roadway can satisfy the requirement for reuse without undercutting, delivering a favorable control effect on the floor heave.

\section{Control Principle of Pressure Relief by Roof Cutting over Floor Heave}

2.1. Theoretical Analysis. The pressure relief by roof cutting can reduce the length of the lateral cantilever beam, and combining with the breaking and swelling characteristics of gangue, the surrounding rock stress environment of the gobside entry can be effectively alleviated [27]. In addition, as a protective cushion, the gangue dump can effectively absorb the kinetic energy of the roof caving process [28] so as to reduce the impact of roof collapse on the floor.

Without roof cutting, the immediate roof in the goaf is caved over a low height, and caved gangues cannot then fill the goaf after being bulked. This leaves a large unfilled space between the suspended main roof and gangue piles in the goaf, as shown in Figure 1(a); after roof cutting, the presence of the cut in the roof leads to an increase in the caving height of the immediate roof of the goaf, and thereby an increase in the volume of the caved gangues. In this way, the goaf can be filled with bulked gangues, thus shrinking the unfilled space between the suspended main roof and gangue piles, as shown in Figure 1(b). According to the bulking characteristics of the caved gangues, the distance $u$ between gangue piles and the suspended main roof can be calculated according to the following equation:

$$
u=H_{G}-H_{c 1}(k-1)-\Delta H
$$

where $u, H_{G}, H_{c 1}, k$, and $\Delta H$ denote the distance between gangue piles and the suspended main roof, mining height, caving height of the immediate roof, bulking factor of rock in the immediate roof, and amount of floor heave in the goaf, respectively.

After the immediate roof is caved, the mass of the rock suspended in the goaf is transferred to coal sides through the rock beam of the main roof, thus increasing the pressure on the coal sides. In this case, the coal sides are still elastically compressed due to failing to reach their ultimate strength and, therefore, the abutment pressure decreases monotonically, with the peak at the coal walls [29], as shown in Figure 1. 


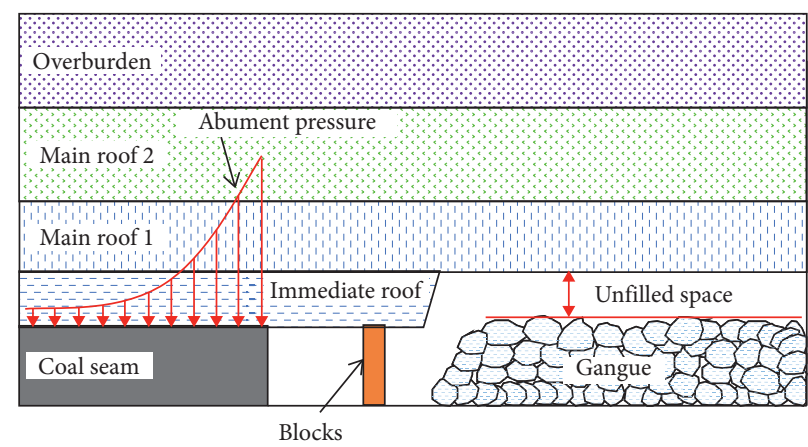

(a)

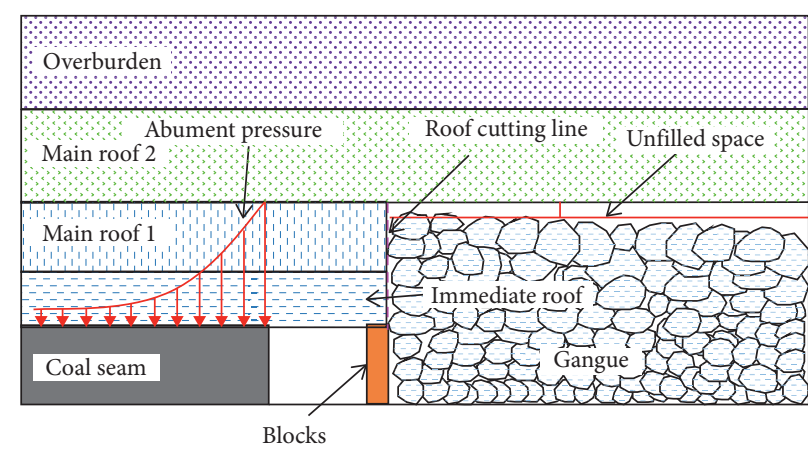

(b)

FIGURE 1: Filling conditions of the goaf after the immediate roof is caved. (a) Conventional mining. (b) Pressure relief by roof cutting.

The rock beam begins to be supported by gangues after it subsides over a certain height, thus making contact with the gangues. The bearing load increases with the increase in the compression of the gangues. Under this condition, as the coal is under elastic compression, the immediate roof below the main roof, coal, and gangues can be considered as elastic media. As a result, the stress prevailing during that subsidence and deformation before fracture of the main roof satisfies the Winkler assumption for an elastic foundation. It is feasible to establish a mechanical model before the fracture of the main roof, as shown in Figure 2.

According to the Winkler assumption for elastic foundation, the deflection of the rock beams of the main roofs above the goaf and coal seams is separately established in the coordinate system, as shown in the following equations:

$$
\begin{aligned}
E I \frac{\mathrm{d}^{4} w_{1}(x)}{\mathrm{d} x^{4}}+k_{1}\left[w_{1}(x)-u\right] & =q_{0}, \\
E I \frac{\mathrm{d}^{4} w_{2}(x)}{\mathrm{d} x^{4}}+k_{1} w_{2}(x) & =q_{0},
\end{aligned}
$$

where $E, I$, and $\omega(x)$ refer to the elastic modulus, moment of inertia, and the deflection of the subsidence zone of the rock beam of the main roof, respectively; $k_{1}$ and $k_{2}$ separately denote the elastic foundation coefficients of gangue piles and coal seams; $u$ and $q_{0}$ represent the distance between the gangue piles and the main roof and the load of the overlying strata on the rock beam of the main roof, respectively.

Assuming $\beta_{1}=\sqrt[4]{\left(k_{1} / 4 E I\right)}$ and $\beta_{2}=\sqrt[4]{\left(k_{2} / 4 E I\right)}$, equations (2) and (3) are solved to reveal the deflections of the main roof above the goaf and coal, as shown in the following equations:

$$
\begin{aligned}
& \omega_{1}=e^{-\beta_{1} x}\left(\frac{\beta_{1}-\beta_{2}}{\beta_{1}+\beta_{2}} \sin \beta_{1} x-\cos \beta_{1} x\right) \cdot\left(\frac{q_{0}}{k_{1}}+u\right)+\frac{q_{0}}{k_{1}}+u, \\
& \omega_{2}=e^{\beta_{2} x}\left(\frac{\beta_{2}-\beta_{1}}{\beta_{1}+\beta_{2}} \sin \beta_{2} x+\cos \beta_{2} x\right) \cdot\left(\frac{q_{0}}{k_{1}}+u\right) \cdot \frac{\beta_{1}^{2}}{\beta_{2}^{2}}+\frac{q_{0}}{k_{2}} .
\end{aligned}
$$

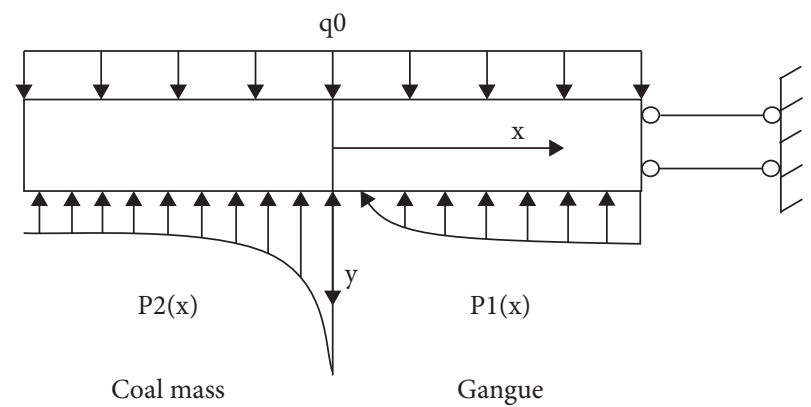

FIGURE 2: Sketch of the stress before the fracture of the main roof.

Therefore, the pressure $p_{1}$ on gangues in the goaf and pressure $p_{2}$ on coal are separately calculated according to the following equations:

$$
\begin{aligned}
p_{1}(x)= & k_{1} e^{-\beta_{1} x}\left(\frac{\beta_{1}-\beta_{2}}{\beta_{1}+\beta_{2}} \sin \beta_{1} x-\cos \beta_{1} x\right) \\
& \bullet\left(\frac{q_{0}}{k_{1}}+u\right)+q_{0}, \\
p_{2}(x)= & k_{2} e^{\beta_{2} x}\left(\frac{\beta_{2}-\beta_{1}}{\beta_{1}+\beta_{2}} \sin \beta_{2} x+\cos \beta_{2} x\right) \cdot\left(\frac{q_{0}}{k_{1}}+u\right) \\
& \bullet \frac{\beta_{1}^{2}}{\beta_{2}^{2}}+q_{0} .
\end{aligned}
$$

As shown in equation (7), the pressure $p_{2}$ applied to the coal sides is mainly related to the distance $u$ between the main roof and gangue piles under the same burial depth and geological conditions. Moreover, pressure $p_{2}$ increases with $u$. By substituting equation (2) into equation (7), the relationship between the pressure $p_{2}$ on the coal sides and the caving height of the immediate roof can be attained as follows: 


$$
\begin{aligned}
p_{2}(x)= & k_{2} e^{\beta_{2} x}\left(\frac{\beta_{2}-\beta_{1}}{\beta_{1}+\beta_{2}} \sin \beta_{2} x+\cos \beta_{2} x\right) \\
& \bullet\left(\frac{q_{0}}{k_{1}}+H_{G}-H_{c 1}(k-1)-\Delta H\right) \bullet \frac{\beta_{1}^{2}}{\beta_{2}^{2}}+q_{0} .
\end{aligned}
$$

It can be seen from equation (8) that the pressure $p_{2}$ on the coal sides decreases with the growth of the caving height $H_{c 1}$ of the immediate roof on the premise of ignoring the influence of floor heave in the goaf and keeping the mining height of the working face the same. In addition, roof cutting by blasting artificially increases the caving height $H_{c 1}$ of the immediate roof, thus decreasing the abutment pressure $p_{2}$ on the coal sides.

The rock beam of the main roof may be fractured at the end after it subsides by a certain amount and an external stress field dependent on the mass of overlying strata is formed outside the fracture line. In this case, the supporting capacity of coal within a certain range away from the roadway side reduces, and coal seams are divided into elastic and plastic zones according to the abutment pressure, as shown in Figure 3.

The pressure in the plastic zone in the external stress field can be calculated according to the following equation [30]:

$$
\begin{aligned}
\sigma_{y} & =\left(\sigma_{c}+\frac{C}{f}\right)\left(1+\frac{\alpha x}{h-\alpha x_{0}}\right)^{2 f / \alpha}, \\
\alpha & =\arctan \frac{y_{0}}{x_{0}},
\end{aligned}
$$

where $\sigma_{y}, \sigma_{c}$, and $C$ refer to the pressure applied on coal seams, the compressive strength of the plastic zone in coal seams, and the cohesion of the interfaces between the coal seam with the roof and floor, respectively; $f, \alpha, h$, and $y_{0}$ represent the coefficient of internal friction of coal seams, compression angle of coal seams, the mining height of the coal, and compression of the coal seams, respectively.

Previous research [29] pointed out that the abutment pressure in the plastic zone increases with the increasing compression angle of coal mass when $x_{0}$ is kept unchanged. In equation (10), the compression angle is shown to be positively correlated with the amount of compression of the coal, and the compression of coal is mainly induced by rotation and subsidence of the overlying rock beams. According to equations (1) and (5), the rotation and subsidence of the main roof decreases after pressure relief by roof cutting. Thus, the compression angle of the coal reduces, and the pressure in the plastic zone in the external stress field decreases.

The pressure in the elastic zone in the external stress field is mainly composed of two parts: the deadweight of the rock beam outside the fracture line and the mass of the suspended rock transferred from the overlying nonfractured strata. Coal is mainly subjected to elastic deformation; thus, it can be supposed that the abutment pressure in the elastic zone is still related to the subsidence of the overlying nonfractured rock beam and increases therewith. After pressure relief by roof cutting, the filling effect of gangues weakens the subsidence of the overlying strata, as shown in Figure 3, thus reducing the abutment pressure of the elastic zone in the external stress field.

Above all, pressure relief by roof cutting can decrease the final subsidence of the main roof and its overlying strata by increasing the total thickness of the caved strata. Therefore, it decreases the abutment pressure applied to the coal sides before the fracture of the rock beam of the main roof and after the stabilization of the surrounding strata.

\subsection{Numerical Simulation}

2.2.1. Engineering Situation. In Faer coal mine located in Liupanshui City, Guizhou Province, China, working face 31004 with a strike length of $983.9 \mathrm{~m}$ and a dip length of $105.8-217.8 \mathrm{~m}$ in the central part of No. 3 mining area was tested. The coal seams with a thickness of 0.59-2.2 $\mathrm{m}$ (an average of $1.8 \mathrm{~m}$ ) showed an average dip angle of $14^{\circ}$ along the strike and were mined by longwall retreat mining along the strike. The roof was controlled by the fully caving method, and the overall height of the coal seam was mined in one operation (Figure 4(a)). The immediate roof and the main roof were composed of silty mudstone with a thickness of $3.1 \mathrm{~m}$ and fine sandstone with a thickness of $6.98 \mathrm{~m}$, respectively, while the immediate floor and the main floor were composed of mudstone with a thickness of $2.6 \mathrm{~m}$ and fine sandstone with a thickness of $8.42 \mathrm{~m}$, respectively (Figure 4(b)).

The cross-section of the retained roadway was a rectangle measuring $4.7 \mathrm{~m} \times 2.6 \mathrm{~m}$ (width $\times$ height). The roadway roof was supported by anchor bolts, anchor cables, ladder beams, and metal mesh. Anchor bolts with a diameter of $20 \mathrm{~mm}$ and a length of $2000 \mathrm{~mm}$ were arranged at spacings of $750 \mathrm{~mm} \times 800 \mathrm{~mm}$. Anchor cables with diameters of $15.24 \mathrm{~mm}$ and lengths of $5000 \mathrm{~mm}$ were arranged at spacings of $1800 \mathrm{~mm} \times 1600 \mathrm{~mm}$. Anchor bolts, ladder beams, and metal mesh were used for supporting the coal wall. The anchor bolts were arranged at spacings of $1000 \mathrm{~mm} \times 800 \mathrm{~mm}$ and had a diameter of $18 \mathrm{~mm}$ and a length of $1800 \mathrm{~mm}$. C30 steel concrete with a density of about $2450 \mathrm{~kg} / \mathrm{m}^{3}$ was used to cast blocks with a mass of about $45 \mathrm{~kg}$, each measuring $650 \mathrm{~mm} \times 190 \mathrm{~mm} \times 190 \mathrm{~mm}$ (length $\times$ width $\times$ thickness). The composition of concrete blocks is water $(9.8 \%)$, C30 cement $(17.6 \%)$, fly ash $(1.8 \%)$, sand $(24.5 \%)$, and gravel $(46.3 \%)$. The support system is shown in Figure 5.

\subsubsection{Establishment of a Numerical Calculation Model.} Numerical simulation is a popular method used to study rock mechanics and engineering and mining problems [31]. Continuum modeling approaches are appropriate with regard to large-scale engineering problems; therefore, the continuous-medium software Flac3D was selected to simulate the deformation characteristics of a roadway roof in the process of roadway retention.

To reveal changes in the stress distribution in the roadway floor before and after roof cutting, a numerical 


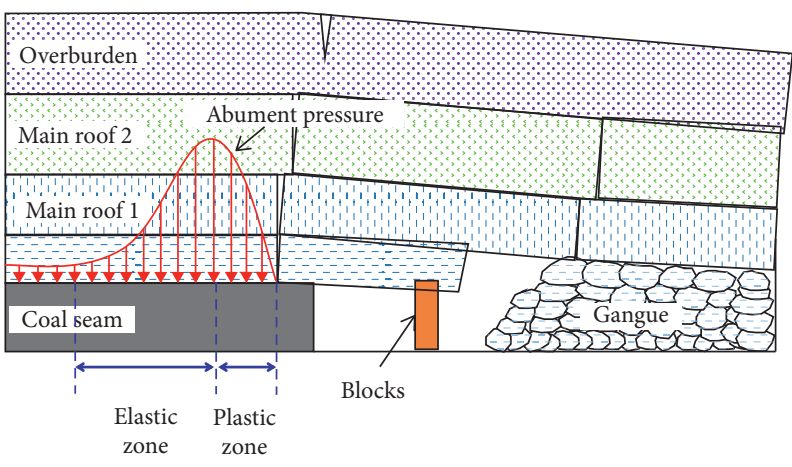

(a)

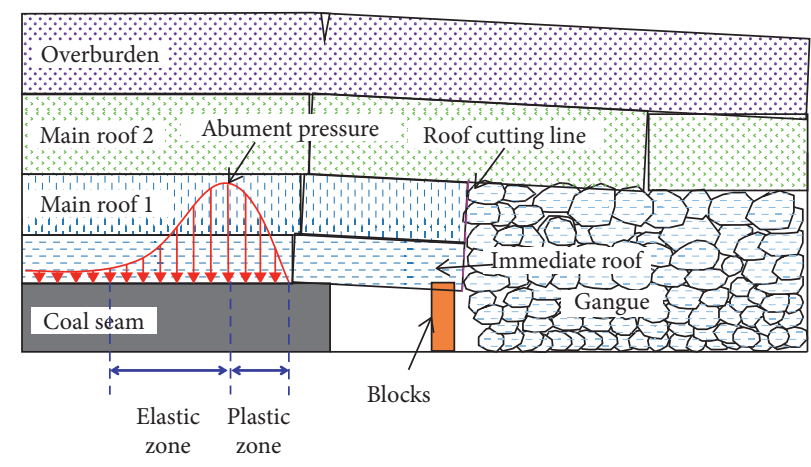

(b)

Figure 3: Distribution of the external stress field. (a) Conventional mining condition. (b) Pressure relief by roof cutting.

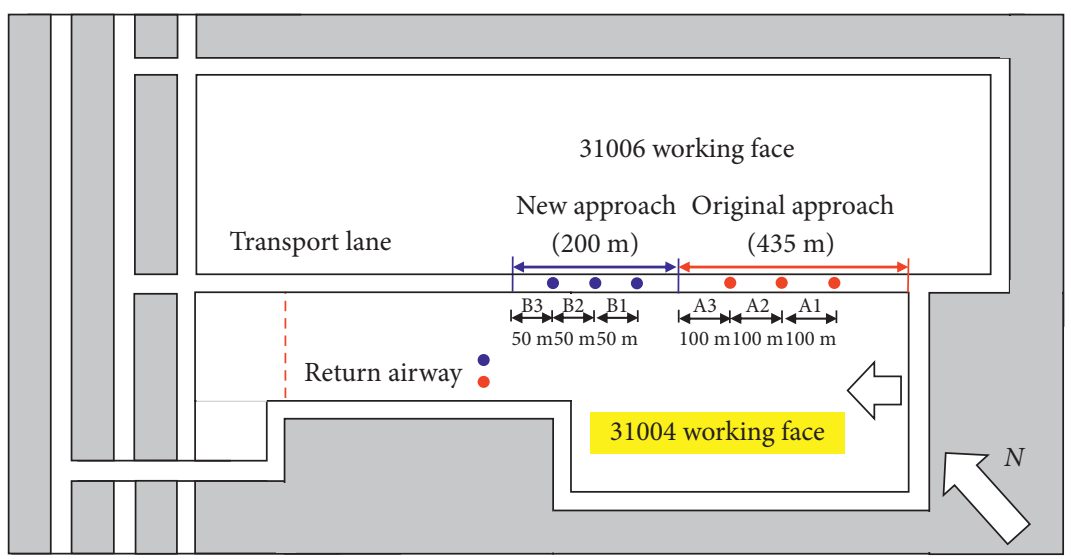

- Measuring point

- Measuring point

\begin{tabular}{|c|c|}
\hline Lithology & Thickness (m) \\
\hline Coal & 2.60 \\
\hline Fine sandstone & 1.17 \\
\hline Shaly sand & 2.40 \\
\hline Fine sandstone & 6.98 \\
\hline Silty mudstone & 3.10 \\
\hline Coal & 1.80 \\
\hline Mudstone & 2.60 \\
\hline Fine sandstone & 8.42 \\
\hline Silty mudstone & 3.10 \\
\hline
\end{tabular}

(b)

Figure 4: Plan layout and lithologic histogram of the working face in the test. (a) Plan layout. (b) Lithologic histogram of the working face.

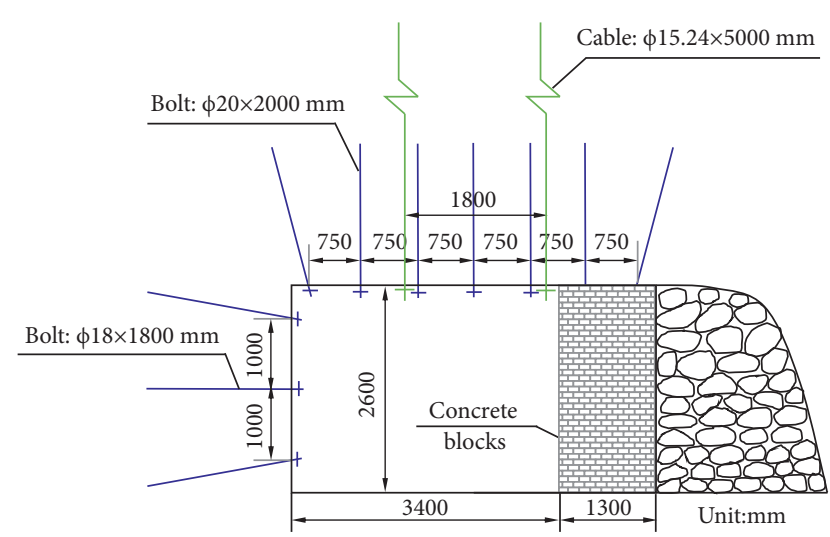

FIGURE 5: Support parameters for the block wall and GER.

calculation model was built by using the three-dimensional finite difference software (Flac3D) based on geological conditions around the 31004 working face in Faer coal mine (Figure 6). The model measured $300 \mathrm{~m} \times 100 \mathrm{~m} \times 85 \mathrm{~m}$ (length $\times$ width $\times$ height) and the working face with the length of $200 \mathrm{~m}$ were simulated. The thickness of coal seams was $2.2 \mathrm{~m}$, and the roadway section measured $3.4 \mathrm{~m} \times 2.6 \mathrm{~m}$. The width of the concrete blocks was $1.3 \mathrm{~m}$. The constitutive model used was the Mohr-Coulomb model, and null elements were used to simulate the working face, roadway excavation, and slitting of the roof. The slotting height in the simulation was $5 \mathrm{~m}$. The stoping face was excavated step-bystep in $5 \mathrm{~m}$ increments. After excavation over $60 \mathrm{~m}$, the final results were calculated. The lithology distribution and physicomechanical parameters of the model are summarised in Table 1.

2.2.3. Analysis of Simulated Results. The data pertaining to the vertical stress on the floor of the retained haulageway were extracted to draw a nephogram with the range of data extraction in Figure 7.

Figure 8 shows the nephogram for the vertical stress in floor. It can be seen from the figure that before pressure relief by roof cutting (Figure 8(a)), the stress concentration in the floor mainly occurs at the coal wall around the roadway during gob-side entry retention. Although a low stress 


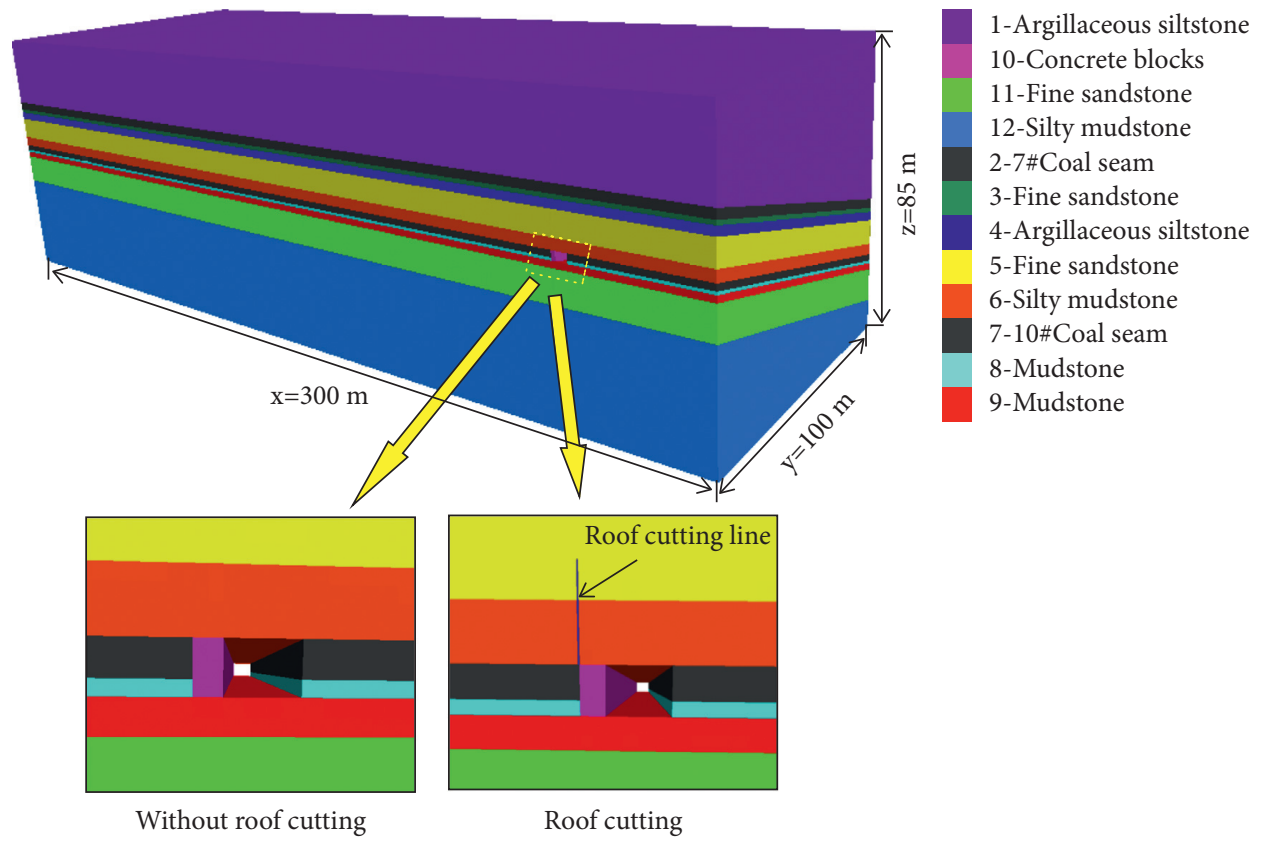

FIgURE 6: Numerical calculation model.

TABLE 1: Physicomechanical parameters of strata.

\begin{tabular}{|c|c|c|c|c|c|c|}
\hline Lithology & Density $/\left(\mathrm{kg} / \mathrm{m}^{3}\right)$ & $\begin{array}{c}\text { Bulk } \\
\text { modulus/(GPa) } \\
\end{array}$ & $\begin{array}{c}\text { Tensile } \\
\text { strength/(MPa) }\end{array}$ & $\begin{array}{c}\text { Shear } \\
\text { modulus/(GPa) }\end{array}$ & $\begin{array}{c}\text { Angle of internal } \\
\text { friction } /\left(^{\circ}\right)\end{array}$ & Cohesion/(MPa) \\
\hline $\begin{array}{l}\text { Argillaceous } \\
\text { siltstone }\end{array}$ & 2,350 & 3.36 & 4.21 & 2.3 & 35 & 1.8 \\
\hline Fine sandstone & 2,570 & 6.25 & 9.5 & 3.57 & 31 & 2.4 \\
\hline Silty mudstone & 2,400 & 10.76 & 1.64 & 3.2 & 30 & 1.4 \\
\hline Coal seam & 1,370 & 2.8 & 0.4 & 1.2 & 27 & 0.6 \\
\hline Mudstone & 2,463 & 3.94 & 1.68 & 2.6 & 30 & 1.2 \\
\hline $\begin{array}{l}\text { C30 concrete } \\
\text { block }\end{array}$ & 2,350 & 7.6 & 2.5 & 11.2 & 32 & 2.1 \\
\hline
\end{tabular}

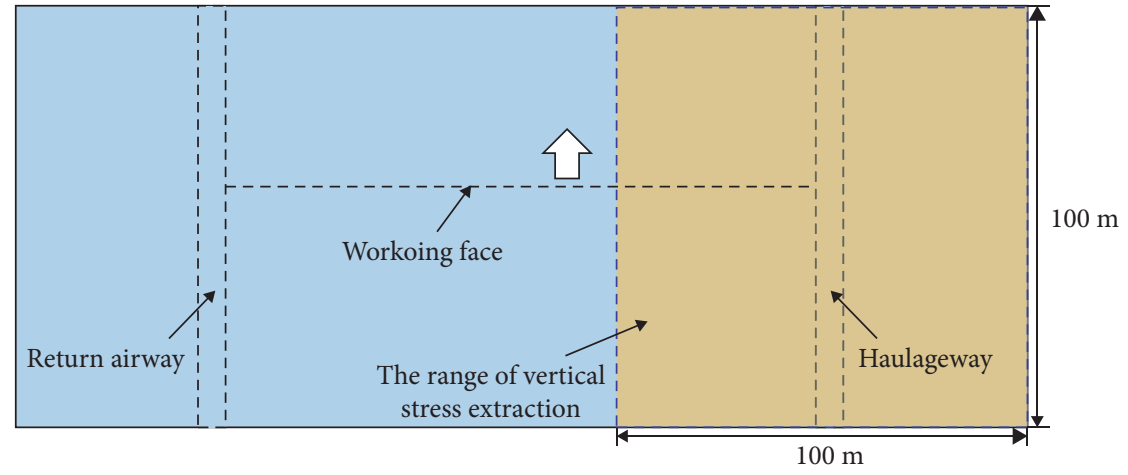

FIGURE 7: Extraction position of vertical stress.

concentration also appears in the floor below the concrete blocks, its average stress is much lower than that of the coal wall, implying that the coal wall acts as the main bearing body of the overburden pressure during gob-side entry retention and the overburden pressure can be transferred to the floor strata below the coal wall through the coal wall. After pressure relief by roof cutting (Figure 8(b)), the stress concentration is still found in the coal wall, while the stress is significantly lower than that beforehand. This shows that pressure relief by roof cutting cannot significantly change the spatial distribution characteristics of the stress on the floor but can reduce the abutment pressure on the coal wall.

To show the spatial distribution of the positions with lowering vertical stress on the floor under the effect of pressure relief by roof cutting, the stress difference is calculated based on Figures 8(a) and 8(b) to draw the 


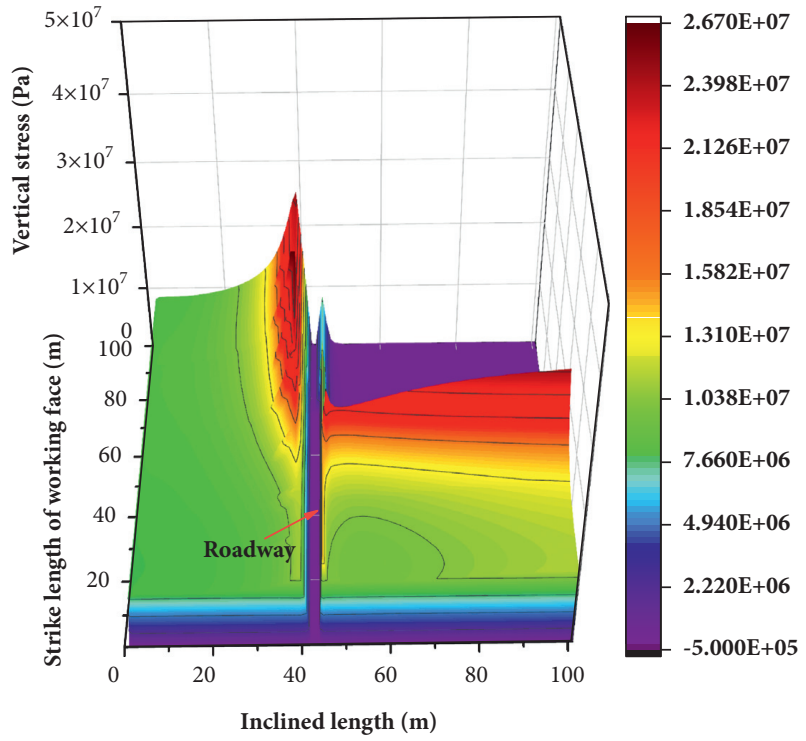

(a)

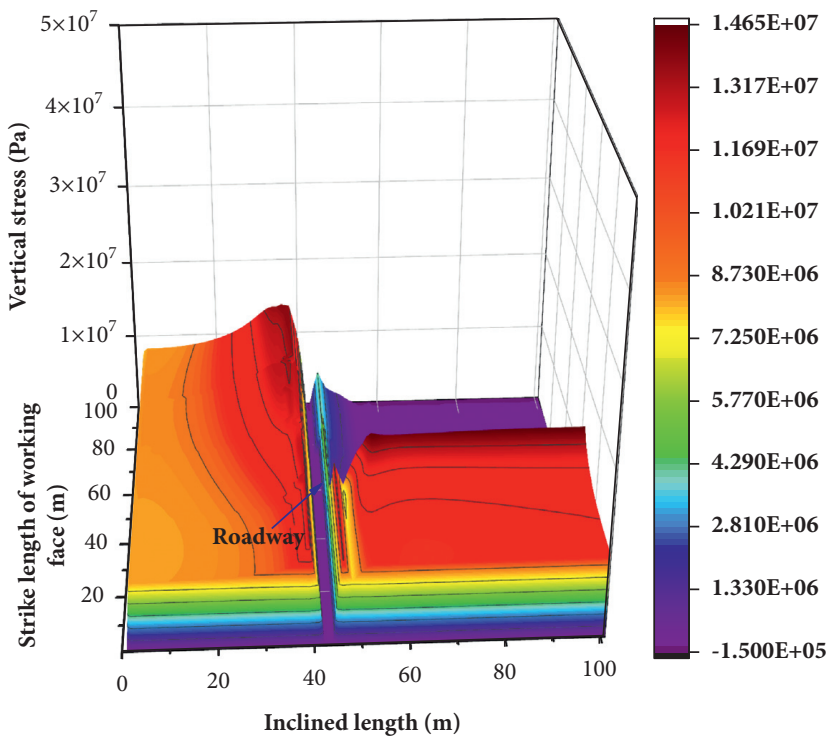

(b)

FIGURE 8: Nephograms of the vertical stress distribution on the floor. (a) Before pressure relief by roof cutting. (b) After pressure relief by roof cutting.

nephogram of the stress difference. In the nephogram, a positive value represents the reduction in the vertical pressure on the floor after roof cutting. A larger value corresponds to a larger reduction in the pressure (Figure 9). The figure shows that pressure relief by roof cutting can decrease the pressure on the floor at three positions (i.e., the coal wall to the rear of the working face, the concrete blocks, and the working face), in which the pressure on the coal wall is the most significantly lowered.

To quantify the changes in vertical stress on the floor of the coal wall during gob-side entry retention before and after pressure relief by roof cutting, survey lines for the pressure were established at 5-m intervals on the floor in the rear of the working face. The survey lines extended from the coal wall along the dip direction of the working face to the boundary of the model. The vertical stresses measured by the survey lines were extracted, and the distribution of the survey lines is shown in Figure 10.

Figure 11 shows the distribution of the vertical stresses taken from different survey lines. As shown in the figure, in terms of the area affected by pressure relief by roof cutting, pressure relief by roof cutting causes significant reduction in the vertical pressure within $15 \mathrm{~m}$ from the coal wall; as for the reduction in peak vertical pressure, within $60 \mathrm{~m}$ to the rear of the working face, the means of the peak vertical stress before and after roof cutting are $2.3 \times 10^{7}$ and $1.3 \times 10^{7} \mathrm{~Pa}$, respectively: the latter declines by $43.5 \%$ relative to the former.

Above all, due to the movement of the overlying strata in the goaf during gob-side entry retention, the vertical stress concentration is generated on the floor in the side of the coal wall and below the block wall in the section of the retained roadway. Pressure relief by roof cutting fails to change the spatial distribution characteristics of the vertical stress on the floor during gob-side entry retention but can reduce the vertical stress. According to the results obtained by numerical simulation, pressure relief by roof cutting can weaken the vertical stress on the floor at up to $15 \mathrm{~m}$ from the coal wall; after pressure relief, the peak vertical stress on the floor in the side of the coal wall within $60 \mathrm{~m}$ of the rear of the working face decreases (on average) by $43.5 \%$, showing a significant pressure-relief effect.

2.3. Comprehensive Analysis. After mining the working face, the abutment pressure $P_{a}$ higher than the in-situ stress $P_{0}$ will be generated in the coal wall of the retained goaf-side roadway and applied to the roadway floor. Furthermore, the floor strata are subjected to lateral stress-relief after being compressed, leading to the increase in the horizontal stress; in comparison, the pressure $P_{a}^{\prime}$ lower than the in-situ stress is formed on the building blocks shielded by overlying strata. The peak abutment pressure $P_{a}$ on the coal wall is calculated according to the following equation [32]:

$$
P_{a}=n P_{0} \text {, }
$$

where $P_{a}, n$, and $P_{0}$ denote the peak abutment pressure, the stress concentration factor (generally, 1.5 to 4.0 ), and the insitu stress, respectively.

According to the above analysis, a mechanical model of the rib and floor can be established (Figure 12). With the advance of the working face, $P_{a}^{\prime}$ and $P_{a}$ both gradually increase. As a result, floors are subjected to plastic failure, and continuous shear-sliding planes are generated. Under the effects of the abutment pressure and the horizontal stress $N$ on the floors, the active state zone AOC will laterally shift to the passive state zone ADE, causing the rock mass to bulge upwards, thus triggering the floor heave (Figure 12(a)). 


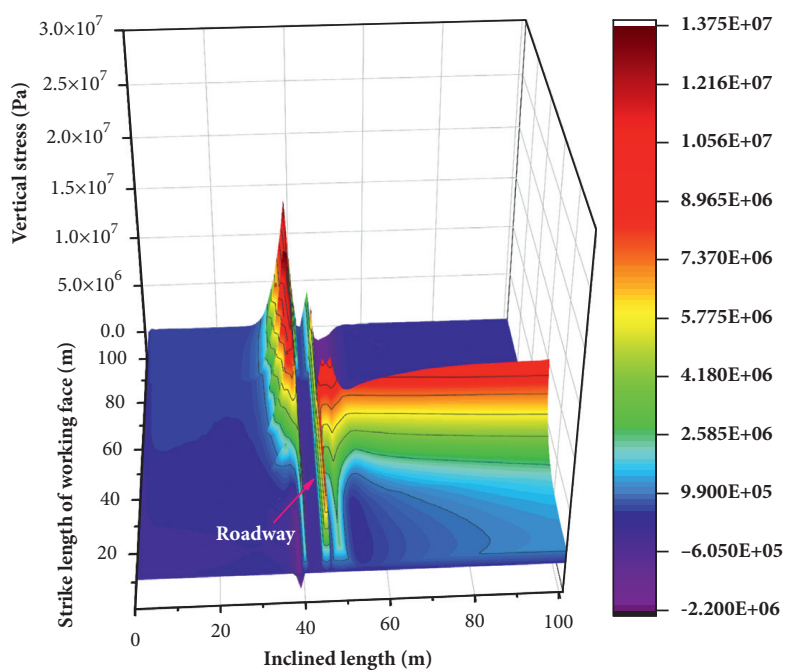

Figure 9: Nephograms of the difference of the vertical stress distribution at the floor before and after the roof cutting.

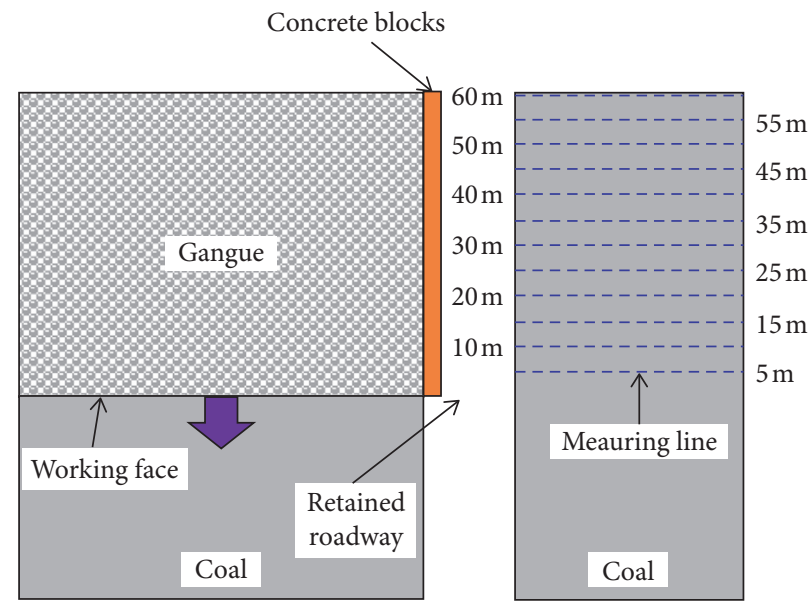

FIGURE 10: Distribution of survey lines for the vertical stress analysis.

$B, P_{u}, q$, and $P_{u}^{\prime}$ represent the width of the abutment pressure zone, the ultimate bearing capacity of the floor, the pressure of backfill layer or track bed or reaction force of the floor support, and the pressure of concrete blocks on the floor, respectively; $\alpha=45^{\circ}-(\varphi / 2)$.

Based on Terzaghi's theory, when floor strata in the range of OCDE are in the plastic state in terms of the limit equilibrium, the ultimate average concentrated stress (or ultimate bearing capacity of the floor) of the sidewall corresponding to width $B$ is expressed as [33]

$$
P_{u}=\frac{1}{2} \gamma B N_{r}+q N_{q}+C N_{c},
$$

where $N_{r}, N_{q}$, and $N_{c}$ indicate the coefficients of bearing capacity and are functions of the angle of internal friction in floor strata. $\quad N_{r} \approx 2\left(N_{q}+1\right) \tan \varphi, \quad N_{q}=e^{\pi \tan \varphi} \tan ^{2}$ $\left(45^{\circ}+(\varphi / 2)\right)$, and $N_{c}=\left(N_{q}-1\right) \times \cot \varphi . C, \varphi$, and $\gamma$ denote the average bonding force, angle of internal friction, and unit weight of rock mass of the floor, respectively.

In the range of width $B$, the average concentrated stress on sidewalls is approximated as follows [32]:

$$
P_{n}=\frac{1}{2} n P_{0}+\frac{L}{2 B} P_{0}
$$

where $L, P_{0}$, and $n$ indicate the width of the elastic pressure zone in the pressure zone, in-situ stress, and stress concentration coefficient, respectively.

It can be seen from Section 2.1 that pressure relief by roof cutting can reduce the abutment pressure applied to the coal wall. As shown in equation (11), under the condition that the in-situ stress $P_{0}$ remains the same, the peak abutment pressure $P_{a}$ is lowered, and, therefore, the stress concentration factor $n$ decreases. It can be seen from equation (13) that the mean concentrated stress $P_{n}$ applied on floors within width $B$ linearly monotonically increases with the stress concentration factor $n$. Thus, $P_{n}$ reduces with decreasing $n$. At $P_{n}<P_{u}$, the floor strata are stable and are not subjected to floor heave (Figure 12(b)).

Therefore, the mechanical principle of pressure relief by roof cutting in controlling the floor heave entails weakening the abutment pressure applied to the coal wall by changing the movement characteristics of overlying strata; this further 


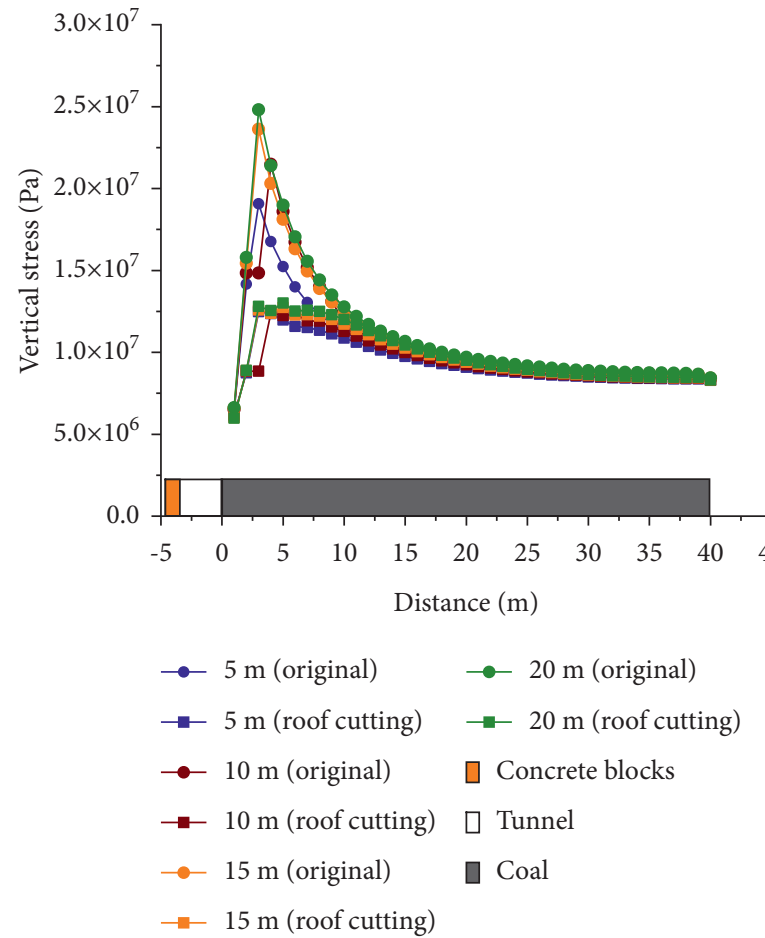

(a)

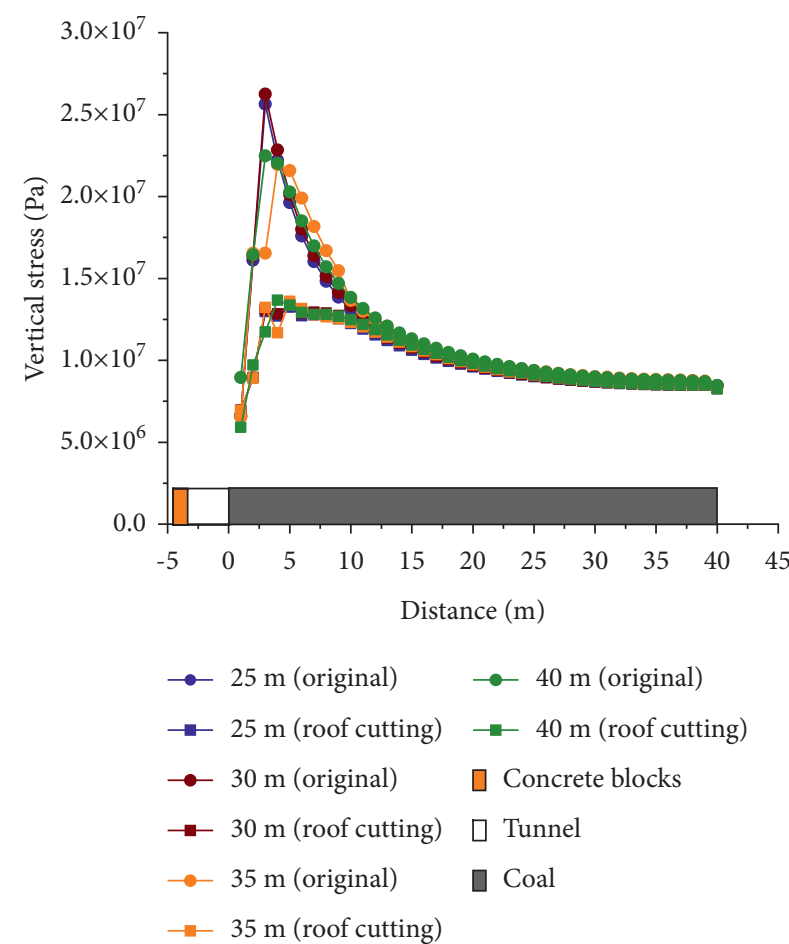

(b)

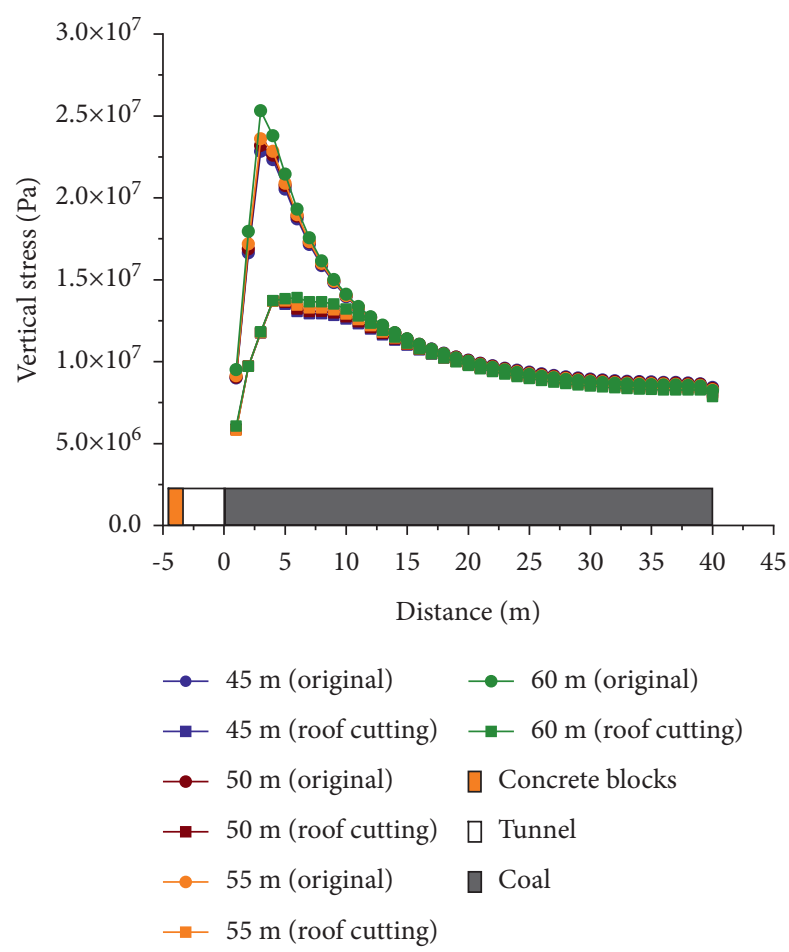

(c)

Figure 11: Distribution of vertical stresses in different parts before and after roof cutting. (a) 5 to $20 \mathrm{~m}$ behind the working face, (b) 25 to $40 \mathrm{~m}$ behind the working face, and (c) 45 to $60 \mathrm{~m}$ behind the working face. 


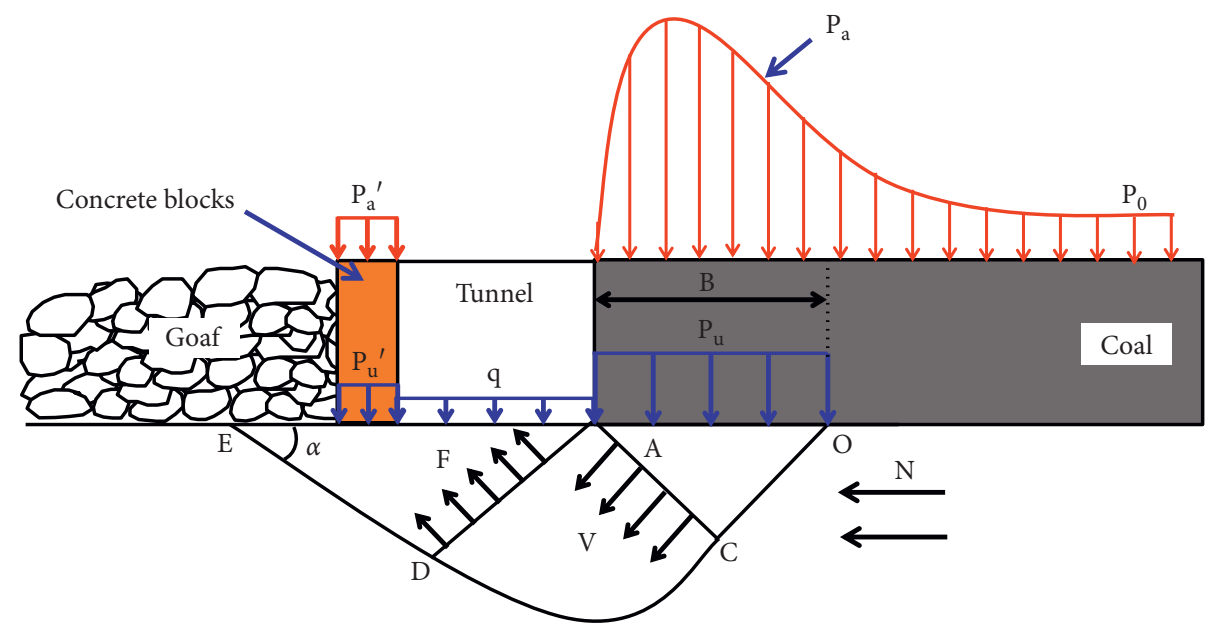

(a)

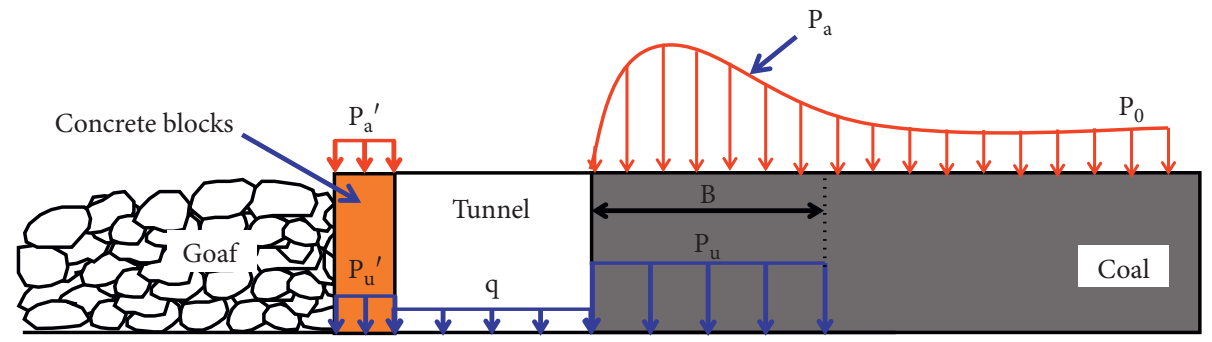

(b)

FIgURE 12: Stress of tunnel rib and floor. (a) Conventional mining condition. (b) Pressure relief by roof cutting.

lowers the pressure exerted by the coal wall on the roadway floor so that the floor strata are not subject to significant plastic and shear failure, thus controlling the floor heave in such roadways.

\section{Key Technique and Technological Processes of Pressure Relief by Roof Cutting in Controlling Floor Heave}

\subsection{Key Technique}

3.1.1. Directional Presplitting Blasting. As one of presplitting blasting, directional presplitting blasting differs from traditional presplitting blasting. It changes the dynamic process of the interaction between detonation waves and surrounding rocks through effective combination of binding energy tubes and ordinary mining explosives. That is, the tangent tensile stress is formed along the direction of the cumulative explosion after ignition. The detonation pressure is transformed into the tensile effect on surrounding rocks to the maximum extent, thus forming an effective fracture surface along the axial direction of roadways [34].

The model for a binding energy tube is shown in Figure 13: holes and slots for cumulative explosion are linearly distributed on the left and right-hand sides of the binding energy tube. After explosives in the binding energy tube are ignited, the tube will curb the propagation of the detonation products. The holes for cumulative explosion linearly distributed in the two sides of the binding energy tube offer the space for pressure relief of the detonation products. As a result, high-energy flows are formed at the holes and impact the hole wall, thus causing the generation of initial cracks in the rock mass.

Thereafter, the high-temperature, high-pressure, and high-speed gases generated due to detonation are still preferentially released from the holes for cumulative explosion following the detonation products in the early period. Moreover, they rapidly propagate along the extension direction of the binding energy tube under the guidance of the slots for cumulative explosion to form air wedges, driving the extension and coalescence of radial initial cracks (Figure 14). Additionally, the detonation products impact the blast hole walls to generate explosion-induced stress waves. Furthermore, compressive stress is generated in the rocks in the radial direction of the blast holes, while a concomitant tensile stress is formed in the circumferential direction. Owing to the tensile strength of rocks being much less than the compressive strength, rocks are fractured under the effect of circumferential tensile stress to form the radial fractures, thus forming an effective fracture surface along such roadways [35].

3.1.2. Coalescence Conditions of Cracks. After cumulative explosions in a single hole, a damaged fracture zone is formed around the hole. To form an effective crack surface along the strike of the roadway roof, it is necessary to perform cumulative explosions with interconnected holes 


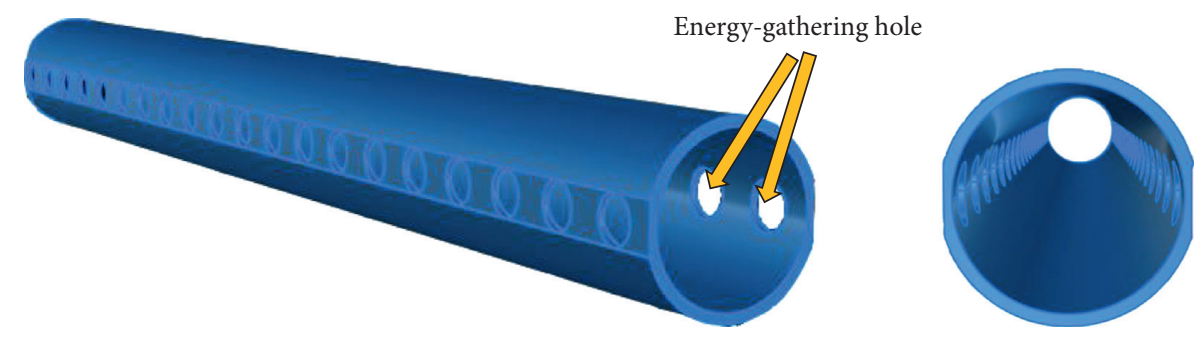

Figure 13: The model for a binding energy tube.
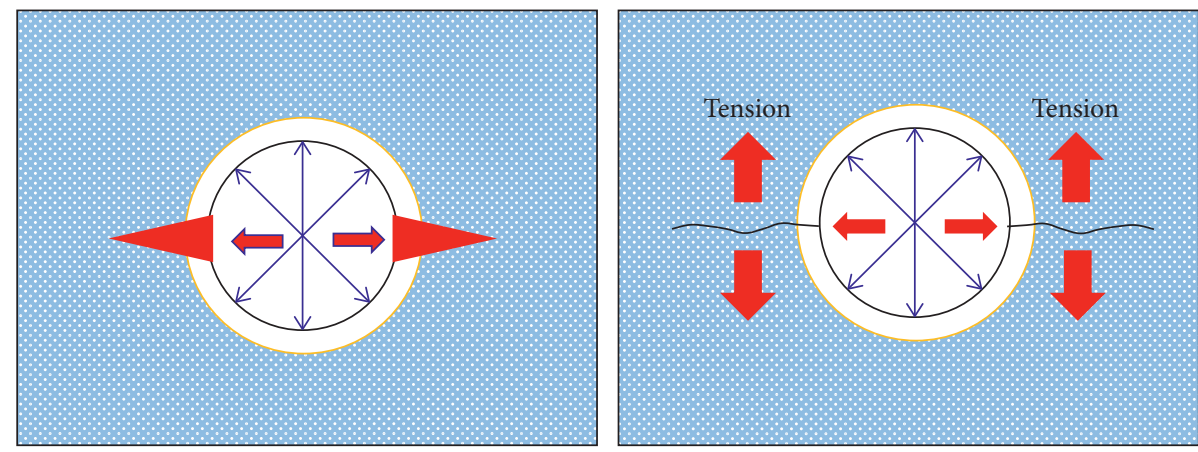

FIGURE 14: The working principle of a directional presplitting blasting.

and make the damaged fracture zones around adjacent blast holes superimposed. Based on the working principle of directional presplitting blasting, it is feasible to establish a mechanical model for the dynamic rock fracture during cumulative explosion with interconnected holes (Figure 15).

According to the attenuation of the explosion-induced stress waves after explosives are ignited, the damage range $R_{\mathrm{s}}$ of the explosion-induced stress can be calculated as shown in the following equation [36]:

$$
R_{s}=r_{b}\left[\frac{\lambda p_{r}}{\left(1-D_{0}\right) \sigma_{t}+p}\right]^{1 / \alpha},
$$

where $\lambda, D_{0}, \sigma_{t}, p, \alpha, p_{r}$, and $r_{b}$ refer to the lateral pressure coefficient, the initial damage in rocks, the tensile strength of rock mass, the in-situ stress, the attenuation index of the explosion-induced stress waves in rock mass, the peak pressure of the detonation products, and the radius of the blast holes, respectively.

To guarantee the coalescence of fractures in adjacent blast holes, the spacing $d$ between blast holes should satisfy the following equation [37]:

$$
d \leq 2 r_{b}\left[\frac{\lambda p_{r}}{\left(1-D_{0}\right) \sigma_{t}+p}\right]^{1 / \alpha} .
$$

As shown in equation (15), during directional presplitting blasting with interconnected holes, a continuous crack surface should be formed along a specific direction if a reasonable spacing between blast holes is designed, thus effectively cutting the roof strata. The field test (Figure 16) showed that effective cracks are formed between blast holes during directional presplitting blasting with interconnected holes, and the surrounding rocks in other directions remain undamaged.

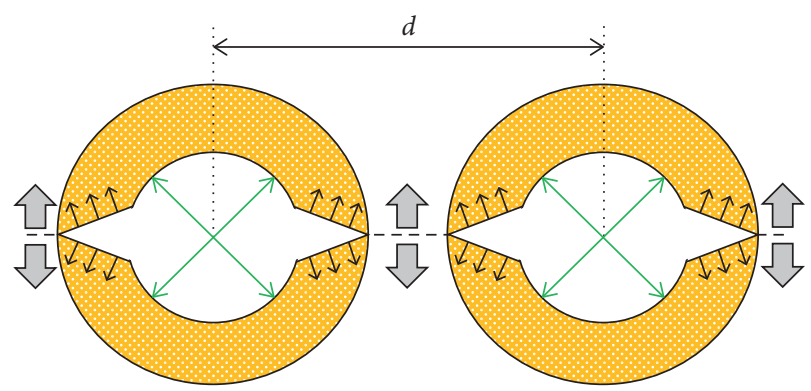

FIgURE 15: The mechanical model for a directional presplitting blasting with interconnected holes.

3.2. Technological Processes. According to the above analysis, the abutment pressure applied on the coal wall leads to floor heave in roadways, while the vertical pressure of the block wall on the floor can inhibit the floor heave to some extent. In addition, rocks are complex geological bodies containing natural microcracks. Cracked rocks are prone to form macrocracks under external conditions, such as engineering disturbances and multifield coupling stress, and results in rock failure [38]. Due to the complexity of rock mass, it is difficult to change its nonlinear characteristics by manual interference, therefore effective reinforcement is necessary [39]. Therefore, while controlling the floor heave, it is essential to reinforce the roof and block wall to prevent plastic failure.

The stress environment of the coal beside the roadway is improved through pressure relief and support to reduce the damage to the floor and enhance the stability of the block walls, thus achieving the goal of controlling the floor heave. Based on this idea, the comprehensive control technique of 


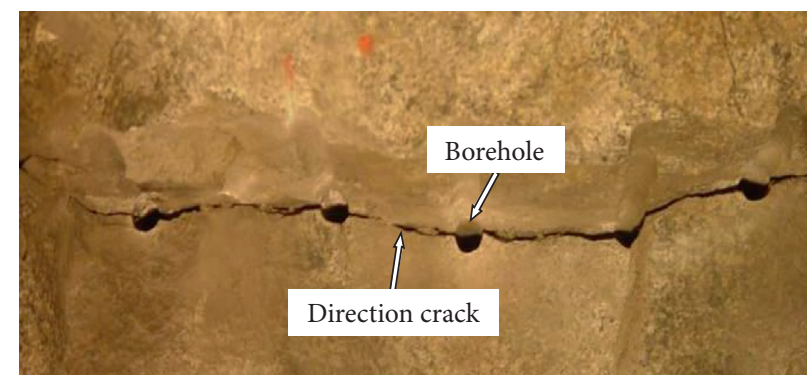

FIGURE 16: The effect of the directional presplitting blasting with interconnected holes [35].

integrating pressure relief by roof cutting, flexible yielding, roadway wall control with double-direction-control bolts, and roof control with reinforcing anchor cables was proposed to solve the difficulties in controlling the floor heave during GER with building blocks. The technological processes of comprehensive control technique for the floor heave are divided into three steps (Figure 17).

Step 1. Support: Advanced reinforcement of roofs; to prevent the immediate roof from showing quite a large settlement after roof cutting through blasting and thereby influencing the global stability of roadways, it is necessary to reinforce the roadway roof with anchor cables before roof cutting. Moreover, the length of the anchor cables should exceed the cutting depth of the roof not be less than $1.5 \mathrm{~m}$ to ensure that the anchored end of the anchor cables lies within the stable roof strata.

Step 2. Cutting: Pressure relief by roof cutting; first, the blast holes are drilled along the designed positions at which it is required that the drilling depth and angle are the same and the blast holes are linearly distributed. The holes are then charged for blasting. The orientation of holes in the binding energy tube should be consistent with the desired direction of extension of cracking. The charge weight in holes, sealing length, and the number of blast holes during each detonation should conform to the design scheme.

Step 3. Protection: Reinforcement of block walls; after pressure relief by roof cutting, the block walls are set with the advance of the working face. While constructing the block walls, the walls are reinforced with double-direction-control anchor bolts combined with ladder-type steel bars; in addition, a certain space for yielding is preserved between walls and the roadway roof, which is filled with flexible materials.

After completing these steps, the overlying strata in the goaf are automatically caved as the working face advances to form a roadway. Under the effect of pressure relief by roof cutting, the gangues in the goaf can support the overlying strata and reduce the rotational subsidence. Furthermore, it can reduce the abutment pressure on the coal wall, thus limiting floor heave in the roadway.

\section{Field Test}

4.1. Parameter Design. By combining the design with the lithology of the roof and mining mode of the working face, the following design parameters are finally determined:

(1) The roof is reinforced by using two rows of ordinary anchor cables with a length of $7 \mathrm{~m}$ made of steel strands with a diameter of $21.6 \mathrm{~mm}$. The first and second rows of anchor cables are, respectively, 600 and $1800 \mathrm{~mm}$ from the roof cutting line. The spacing and row spacing of anchor cables are set as $1200 \times 1600 \mathrm{~mm}$ (Figure 18(a)).

(2) According to the theory of bulking of a rock mass, the cutting depth of the roof during presplitting is designed as follows [31]:

$$
H_{F}=\frac{M-\Delta H_{1}-\Delta H_{2}}{K-1} .
$$

(i) $H_{F}, M, \Delta H_{1}, \Delta H_{2}$, and $K$ denote the cutting height $(\mathrm{m})$ of the roof, the mining height $(\mathrm{m})$, the roof subsidence $(\mathrm{m})$, the floor heave $(\mathrm{m})$, and the bulking factor (1.45) of the roof strata.

(ii) According to the prevailing conditions in Faer Coal Mine, the maximum mining height is determined to be $2.2 \mathrm{~m}$. Ignoring the roof subsidence and floor heave in the goaf, the cutting depth of the roof is calculated to be $4.9 \mathrm{~m}$ after substituting the mining height into the equation. Eventually, the depth of the roof cut vertically upward is determined to be $5 \mathrm{~m}$.

(iii) The class- 3 emulsion explosives (measuring $\varphi$ $32 \times 300 \mathrm{~mm}$ ) are applied during downhole blasting and three rolls of explosives are distributed in each hole (Figure 18(b)). The energy is accumulated along the strike of the roadway with the sealing length of $2 \mathrm{~m}$ and the spacing between blast holes of $500 \mathrm{~mm}$.

(3) The block wall is reinforced with double-directioncontrol anchor bolts. The anchor rod is right-handed full thread steels with $\varphi$ of $18 \mathrm{~mm}$ and a length of $1600 \mathrm{~mm}$. Three rows of anchors are installed: the anchors arranged in the top and bottom of the wall 


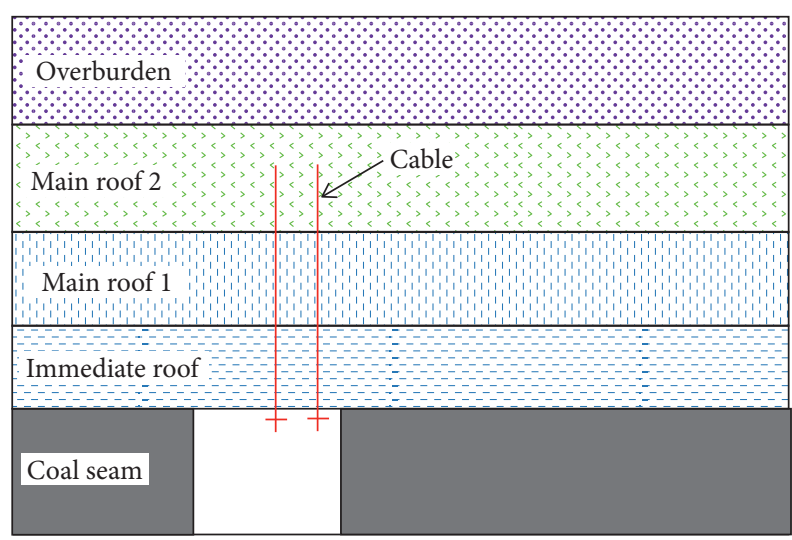

(a)

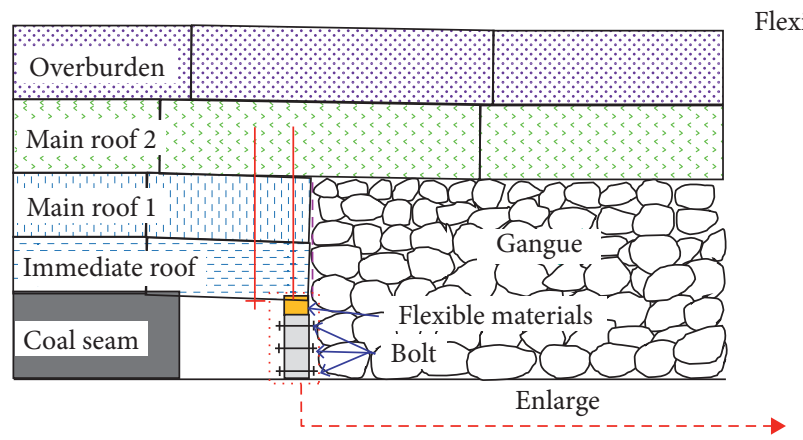

(c)

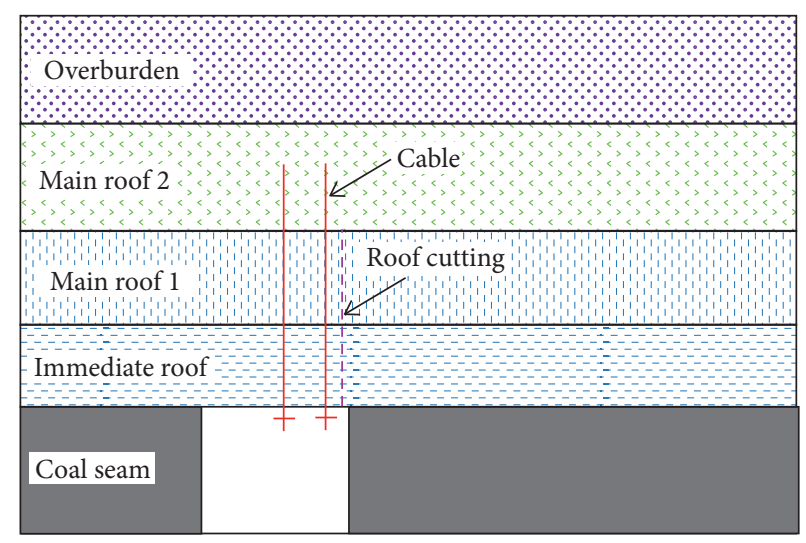

(b)

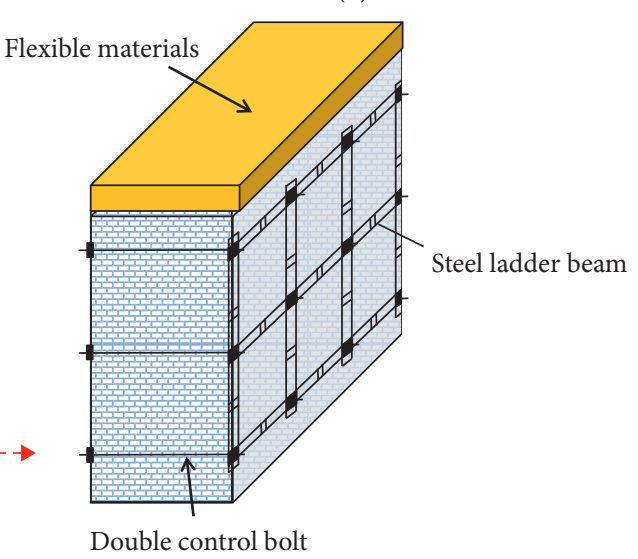

FIGURE 17: Technological processes. (a) Support: advanced reinforcement of roofs. (b) Cutting: pressure relief by roof cutting. (c) Protection: reinforcement of block walls.

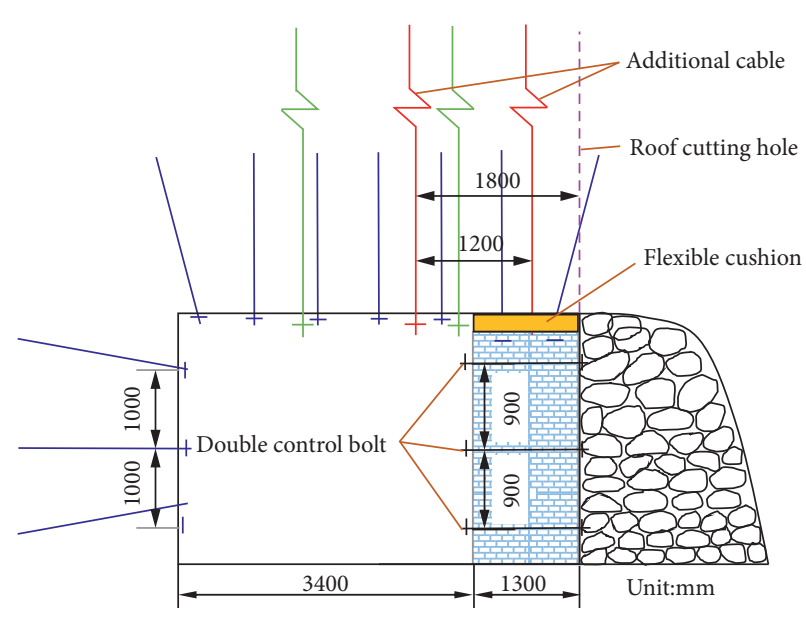

(a)

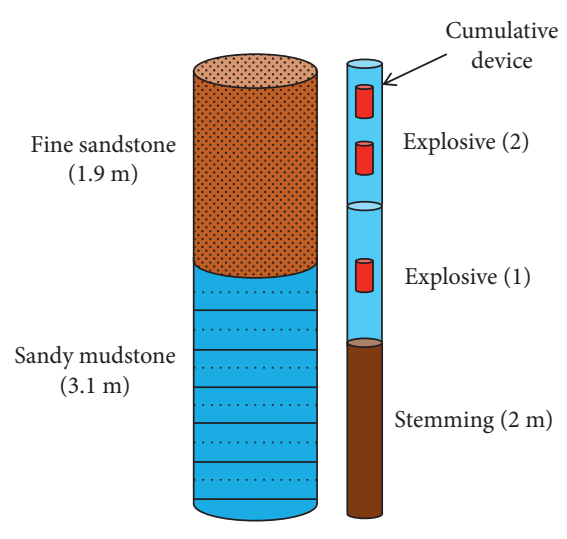

(b)

FIGURE 18: The new control scheme for floor heave and charge structure. (a) The control scheme for floor heave; (b) charge structure.

are both $300 \mathrm{~mm}$ from the top of the wall and the floor, with the spacing and row spacing of anchors set to $900 \times 1000 \mathrm{~mm}$. The lateral and longitudinal ladder-type steel bars are distributed on the anchors on the outer side of the wall (roadway side) and lapped end-to-end. The lap joint is fixed with the supporting pallet and nuts. The space for the yield of $200 \mathrm{~mm}$ is retained between the wall top and the 


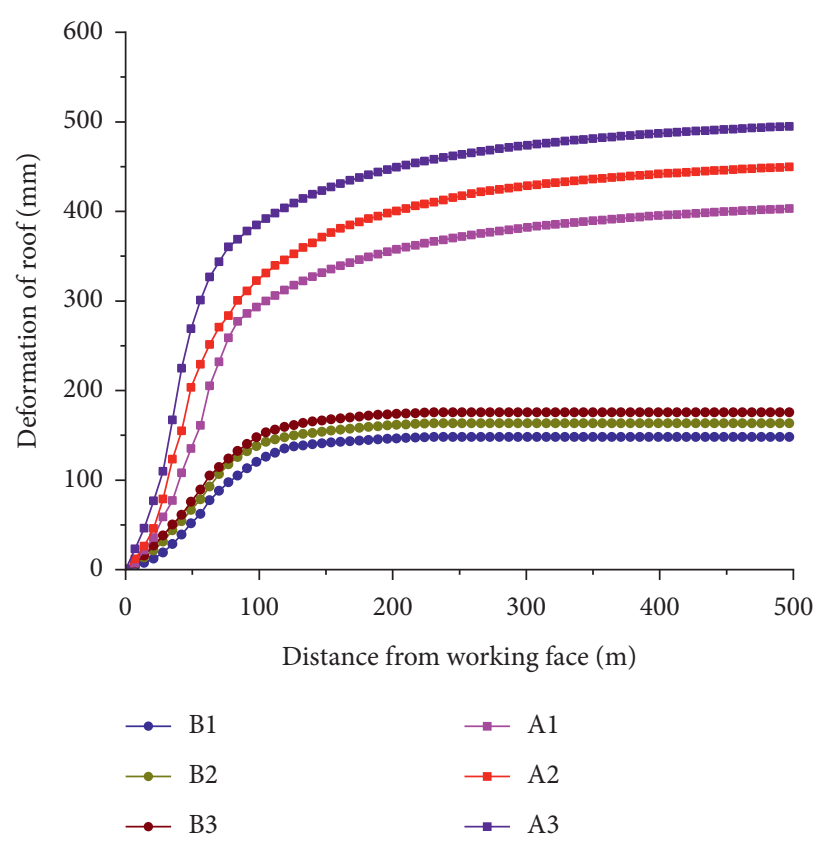

(a)

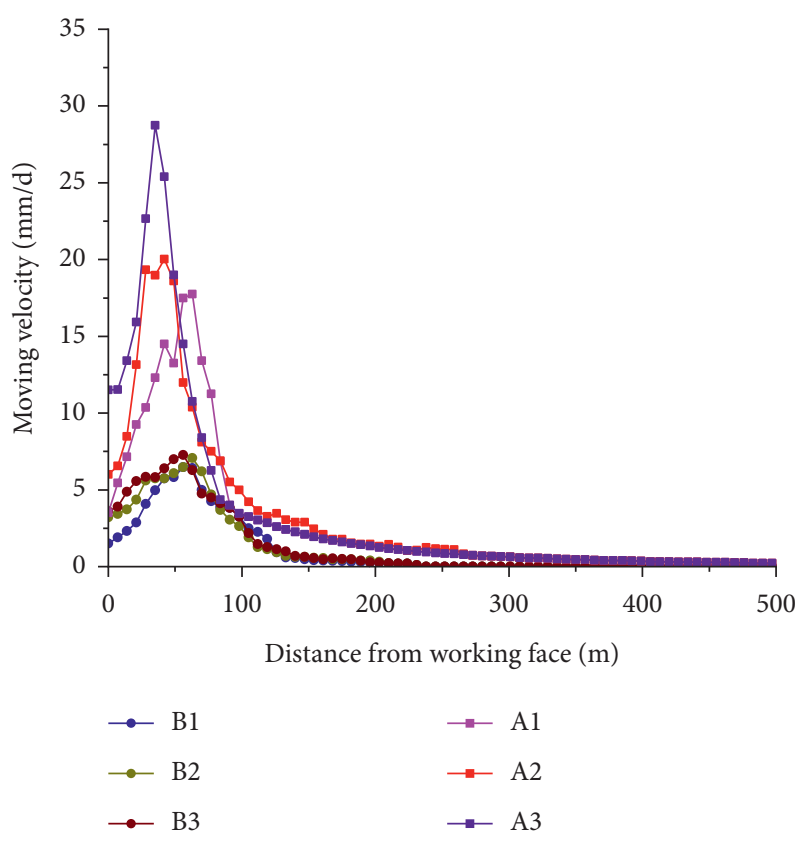

(b)

FIGURE 19: Comparison of the floor deformation before and after the controlling floor heave. (a) Comparison of the amount of deformation. (b) Comparison of the rate of deformation.

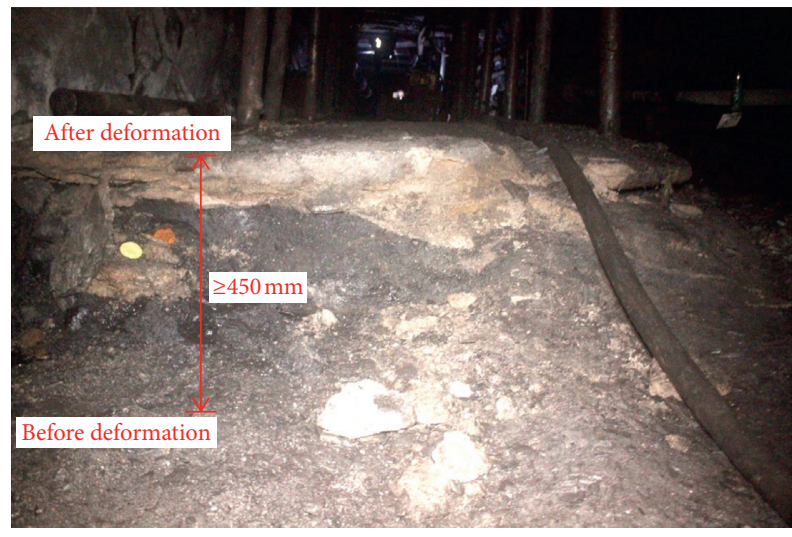

(a)

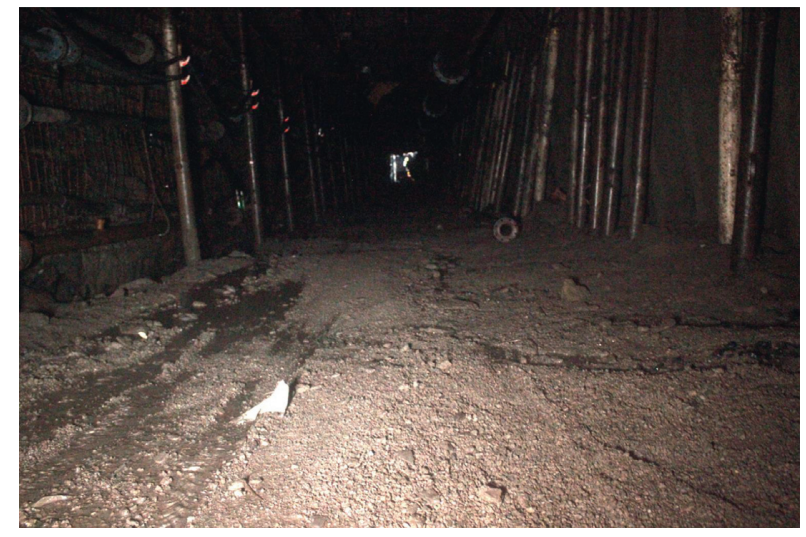

(b)

FIgURe 20: The control effect on floor heave. (a) Before control. (b) After control.

roadway roof and filled with high-water-content materials injected by using flexible bags (Figure 18(a)).

4.2. Effect Analysis. The aforementioned technical scheme is applied to the conveyor gateway of No. 31004 working face. After completion, the convergence of the roadway floor during gob-side entry retention is monitored. The distribution of the monitoring points is shown in Figure 4(a). Points A1 to A3 represent the measuring points for the floor heave of the roadway before control scheme, with a spacing of $100 \mathrm{~m}$; points B1 to B3 are monitoring points for the floor heave of the roadway after control scheme, and are at a spacing of $50 \mathrm{~m}$. The rate of convergence of the floor during gob-side entry retention calculated according to the convergence of the floor and a comparison is made with the deformation characteristics of the floor before controlling the floor heave (Figure 19).

Figure 19 shows the comparison of the deformation of the floor before and after controlling the floor heave: the roadway is persistently subjected to the floor heave during gob-side entry retaining under the original technical scheme. It can be seen from research [40] that the floor heave process of roadway has obvious creep characteristics. Until reaching the position $500 \mathrm{~m}$ to the rear of the working face, the average floor heave amount at three monitoring points is $450 \mathrm{~mm}$; after applying the new technique for controlling the 
floor heave, the floor heave does not occur any longer around a position some $231 \mathrm{~m}$ to the rear of the working face. The average floor heave in the roadway is $162.3 \mathrm{~mm}$ after controlling the floor heave, and the total floor heave decreases by $64 \%$ compared with that before; the average rate of floor heave is $6.4 \mathrm{~mm} / \mathrm{d}$ within the first $231 \mathrm{~m}$ to the rear of the working face under the original technical scheme; after applying the comprehensive control technique for floor heave, the average rate of floor heave is $2.5 \mathrm{~mm} / \mathrm{d}$ within the first $200 \mathrm{~m}$ to the rear of the working face (a reduction of $61 \%)$. The roadway floor shows favorable evenness after controlling the floor heave and multiple undercutting operations before roadway retention and reuse are avoided, which can satisfy the requirement on the reuse of the roadway (Figure 20).

\section{Conclusions}

The mechanical principle of controlling the floor heave based on pressure relief by roof cutting was explored by using theoretical analysis and numerical simulation; furthermore, a novel control technique for floor heave with pressure relief by roof cutting as the core and its technological processes were determined. Moreover, according to the engineering example, the application effect of the technique in engineering practice was discussed. The following conclusions are drawn:

(1) Based on the theory of beam on elastic foundation, a mechanical model for the main roof was established, and the mathematical relationship between the abutment pressure on the coal sides and the caving height of the immediate roof in the goaf was derived. On this basis, the mechanical principle for controlling the floor heave based on pressure relief by roof cutting was attained. To be specific,

(i) Pressure relief by roof cutting increases the caving height of the immediate roof in the goaf. In this case, after being bulked, the caved gangues can be filled into the goaf and support the suspended main roof, which reduces the subsidence amount of the main roof and thus decreases the abutment pressure on the coal sides.

(ii) After the pressure applied to the coal sides drops, the pressure transferred to the roadway floor through the coal sides also decreases. Thus, the floor is not subjected to significant plastic failure, thus controlling floor heave in the roadway.

(2) Through numerical simulation, the pressure-relief effect of the roof cutting through blasting was verified. Under the effect of pressure relief by roof cutting, the abutment pressure within the first $15 \mathrm{~m}$ from the roadway sidewall is reduced; after pressure relief by roof cutting, the average peak vertical stress on the floor in the side of the coal wall within the gob-side entry retention range of 0 to $40 \mathrm{~m}$ to the rear of the working face decreases by $43.5 \%$, showing a remarkable pressure-relief effect.

(3) A new integrated technique for controlling the floor heave based on pressure relief by roof cutting, flexible yielding, controlling with double-directioncontrol anchor bolts, and controlling with reinforcing anchor cables centred on pressure relief by roof cutting was proposed. The technological processes involving three steps, i.e., support, cutting, and protection, were summarised.

(4) The field test result shows that the roadway floor becomes stable at a position some $231 \mathrm{~m}$ to the rear of the working face after employing the new technique. Compared with the original technique, the average floor heave amount during gob-side entry retention decreases by $64 \%$; the average rate of floor heave within the first $231 \mathrm{~m}$ to the rear of the working face drops by $61 \%$, delivering a favorable control effect on the floor heave.

\section{Data Availability}

The data used to support the findings of this study are available from the corresponding author upon request.

\section{Conflicts of Interest}

The authors declare that there are no conflicts of interest regarding the publication of this paper.

\section{Acknowledgments}

This research was funded by the National Natural Science Foundation of China (No. 52074300) and the State Key Laboratory for GeoMechanics and Deep Underground Engineering, China University of Mining \& Technology, Beijing (No. SKLGDUEK2020).

\section{References}

[1] M. C. He, H. P. Xie, S. P. Peng, and Y. D. Jiang, "Study on rock mass mechanics in deep mining," Chinese Journal of Rock Mechanics and Engineering, vol. 24, no. 16, pp. 2803-2813, 2005.

[2] X. Z. Hua, "Study on gob-side entry retaining technique with roadside packing in longwall top-coal caving technology," Journal of Coal Science and Engineering, vol. 10, no. 1, pp. 9-12, 2004.

[3] A. Azadeh, M. Osanloo, and M. Ataei, "A new approach to mining method selection based on modifying the Nicholas technique," Applied Soft Computing, vol. 10, no. 4, pp. 1040-1061, 2010.

[4] H. Basarir, Y. Sun, and G. Li, "Gateway stability analysis by global-local modeling approach," International Journal of Rock Mechanics and Mining Sciences, vol. 113, pp. 31-40, 2019.

[5] D. Y. Zhu, W. L. Gong, Y. Su, and A. Guo, "Application of high-strength lightweight concrete in gob-side entry retaining in inclined coal seam," Advances in Materials Science and Engineering, vol. 2020, Article ID 8167038, 20 pages, 2020.

[6] S. R. Xie, E. Wang, D. D. Chen et al., "Failure analysis and control mechanism of gob-side entry retention with a $1.7-\mathrm{m}$ 
flexible-formwork concrete wall: a case study," Engineering Failure Analysis, vol. 117, 2020.

[7] J. B. Bai, H. Q. Zhou, and C. J. Hou, "Development of support technology beside roadway in goaf-side entry retaining for next sublevel," Journal of China University of Mining \& Technology, vol. 33, no. 2, pp. 183-186, 2004.

[8] X. Z. Hua, X. Y. Lu, and Y. F. Li, "Prevention and control technology of floor heave in gob-side entry retaining with large section of deep mine," Coal Science and Technology, vol. 41, no. 3, pp. 100-104, 2013.

[9] F. Wu, H. Zhang, Q. L. Zou, C. B. Li, J. Chen, and R. Gao, "Viscoelastic-plastic damage creep model for salt rock based on fractional derivative theory," Mechanics of Materials, vol. 150, 2020.

[10] M. Yang and X. Z. Hua, "Development orientation and status of floor heave for gob-side entry retaining in China," Safety in Coal Mines, vol. 46, no. 12, pp. 213-217, 2015.

[11] J. B. Bai, W. F. Li, X. Y. Wang et al., "Mechanism of floor heave and control technology of roadway induced by mining," Journal of Mining \& Safety Engineering, vol. 28, no. 1, pp. 1-5, 2011.

[12] M. C. He, G. F. Zhang, G. L. Wang, Y. L. Xu, C. Z. Wu, and Q. D. Tang, "Research on mechanism and application to floor heave control of deep gateway," Chinese Journal of Rock Mechanics and Engineering, vol. 28, pp. 2593-2598, 2009.

[13] Q. S. Liu, X. W. Lie, X. Huang, and B. Liu, "Research on the floor heave reasons and supporting measures of deep softfractured rock roadway," Journal of China Coal Society, vol. 38, no. 4, pp. 566-571, 2013.

[14] G. X. Xie and J. C. Chang, "Study on overcutting-bolting \& grouting-backfilling concrete to control the floor heave of deep mine," Journal of China Coal Society, vol. 35, no. 8, pp. 1242-1246, 2010.

[15] L. S. Gao, X. J. Zheng, Y. C. Wang et al., "Study on mechanism of pressure relief by deep hole blasing and technique system to control floor heave on the road way floor," China Mining Magazine, vol. 29, no. 8, pp. 104-110, 2020.

[16] J. Sun, "Numerical simulation of grooving method for floor heave control in soft rock roadway," International Journal of Mining Science and Technology, vol. 21, no. 1, pp. 49-56, 2011.

[17] H. B. Zhao, Y. H. Liu, H. Cheng et al., "Mechanism and prevention measures of asymmetric floor heave in mining roadway of Huipodi coal mine," Journal of Mining Science and Technology, vol. 5, no. 6, pp. 638-647, 2020.

[18] J. Lu, P. L. Gong, and P. Li, "Research on the mechanism of floor heave and borehole pressure relief technology in deep soft rock roadway," Journal of Mining Science ang Technology, vol. 46, no. 6, pp. 35-41, 2019.

[19] L. Han, S. Y. Hou, and X. K. Zhang, "Mechanism and control technology of floor heave in mining roadway of large dip coal seam," Safety in Coal Mines, vol. 49, no. 3, pp. 209-212, 2018.

[20] J. J. Wang, J. H. Wang, X. G. Ma et al., "Research on pressure relief by hydraulic fracturing technology of 68310 ventilation roadway in Duerping coal mine," Modern Mining, vol. 36, no. 11, pp. 72-75, 2020.

[21] Z. A. Cao, Y. M. Liu, M. S. Gao et al., "Study on down-ward borehole bolt and grouting reinforcement technology of mine soft and weak mudstone roadway floor," Coal Science and Technology, vol. 44, no. 3, pp. 12-17, 2016.

[22] G. Feng, Y. Kang, X. Wang, Y. Hu, and X. Li, "Investigation on the failure characteristics and fracture classification of shale under brazilian test conditions," Rock Mechanics and Rock Engineering, vol. 53, no. 7, pp. 3325-3340, 2020.

[23] B. Su, B. Ma, Y. J. Feng et al., "Development of new-style multi-function drilling machine platform and its application in hydro-fracture," Coal Mining Technology, vol. 20, no. 4, pp. 140-142, 2015.

[24] M. C. He, W. F. Cao, and R. L. Shan, "New blasting technology-bilateral cumulative tensile explosion," Chinese Journal of Rock Mechanics and Engineering, vol. 12, pp. 2407-2051, 2003.

[25] Q. Wang, M. C. He, S. C. Li et al., "Comparative study of model tests on automatically formed roadway and gob-side entry driving in deep coal mines," International Journal of Mining Science and Technology, vol. 31, no. 4, pp. 591-601, 2021.

[26] Q. Wang, Y. Wang, M. C. He et al., "Experimental research and application of automatically formed roadway without advance tunneling," Tunnelling and Underground Space Technology, vol. 114, no. 3, 2021.

[27] Y. Zhang, H. C. Xu, P. Song, X. M. Sun, M. C. He, and Z. B. Guo, "Stress evolution law of surrounding rock with gobside entry retaining by roof cutting and pressure release in composite roof," Advances in Materials Science and Engineering, vol. 2020, Article ID 1961680, 15 pages, 2020.

[28] C. Zhu, M.-C. He, M. Karakus, X.-H. Zhang, and Z. Guo, "The collision experiment between rolling stones of different shapes and protective cushion in open-pit mines," Journal of Mountain Science, vol. 18, no. 5, pp. 1391-1403, 2021.

[29] Z. Q. Song, Practical Method of Mine Pressure Control, China University of Mining and Technology Press, Xuzhou, China, 1988.

[30] Y. L. Tan, Ground Pressure and Strata Control, China Coal Industry Publishing House, Beijing, China, 2008.

[31] B. Li, R. Bao, Y. Wang, R. Liu, and C. Zhao, "Permeability evolution of two-dimensional fracture networks during shear under constant normal stiffness boundary conditions," Rock Mechanics and Rock Engineering, vol. 54, no. 3, pp. 1-20, 2021.

[32] J. Z. Yang, "A study on mechanism of tunnel floor-heave," Yunnan Metallurgy, vol. 27, no. 4, pp. 12-15, 1998.

[33] J. F. Pan, "Start-up principium of rock burst in whole coal roadway floor in half-island face," Journal of China Coal Society, vol. 36, no. S2, pp. 332-338, 2011.

[34] M. C. He, P. F. Guo, X. H. Zhang, and J. Wang, "Directional presplitting of roadway roof based on bidirectional shaped sharge tension blasting theory," Explosion and Shock Waves, vol. 38, no. 4, pp. 795-803, 2018.

[35] X. Y. Zhang, J. Z. Hu, H. J. Xue et al., "Innovative approach based on roof cutting by energy-gathering blasting for protecting roadways in coal mines," Tunnelling and Underground Space Technology, vol. 99, pp. 1-12, 2020.

[36] H. Jia and Y. Xu, "Study on stress damage zone in excavation of rock mass," Chinese Journal of Rock Mechanics and Engineering, vol. 26, pp. 3489-3942, 2007.

[37] M. C. He, Y. B. Gao, J. Yang et al., "An energy-gathered roof cutting technique in no-pillar mining and its impact on stress variation in surrounding rocks," Chinese Journal of Rock Mechanics and Engineering, vol. 36, no. 6, pp. 1314-1325, 2017.

[38] G. Feng, X. C. Wang, M. Wang, and Y. Kang, "Experimental investigation of thermal cycling on fracture characteristics of 
granite in a geothermal-energy reservoir," Engineering Fracture Mechanics, vol. 235, 2020.

[39] C. Zhu, M. C. He, X. H. Zhang, Z. G. Tao, Q. Yin, and L. F. Li, "Nonlinear mechanical model of constant resistance and large deformation bolt and influence parameters analysis of constant resistance behavior," Rock and Soil Mechanics, vol. 42, no. 7, pp. 1911-1924, 2021.

[40] F. Wu, R. B. Gao, J. Li, and C. B. Li, "New fractional variableorder creep model with short memory," Applied Mathematics and Computation, vol. 380, 2021. 